\title{
LEARNING ATTAINMENTS AS A RESULT OF STUDENT ACTIVITY, COGNITION AND THE CLASSROOM ENVIRONMENT
}

PROBLEMS

OF EDUCATION

IN THE $21^{\text {st }}$ CENTURY Volume 41,2012

\author{
Harri Pitkäniemi, Petteri Vanninen \\ University of Eastern Finland, Savonlinna, Finland \\ E-mail: harri.pitkaniemi@uef.fi, petteri.vanninen@uef.fi
}

\begin{abstract}
The purpose of the study was to construct a model to comprehensively describe the relationships between the classroom learning environment, student's cognition (student mediation) and learning outcomes. In studies of the learning environment, mostly direct (distal) connections have been investigated in relationships between psycho-social properties and learning outcomes. Aspects of student mediation (proximal), such as student's self-efficacy and metacognition, have also often been overlooked in traditional teacher effectiveness research. Using a model that includes mediation variables and that allows for indirect connections between variables increases understanding of how these mechanisms interact. A questionnaire was used to collect data from 218 fifth-and sixth-grade students in Finnish comprehensive schools (girls, $N=116$; boys, $N=102$ ). Drawing on prior research findings, a conceptual model was first developed to identify the range of statistically significant relationships between the learning environment, student's cognition and learning attainment. To further develop the model, a number of modification indices of the AMOS program were employed and then the revised model was tested. The goodness of fit indices for the re-specified model provided evidence for an adequate fit to the data. It was concluded that qualities of classroom learning, including metacognitive orientation, student-teacher relationships and conditions for studying, will have both indirect and direct effects on student's cognition and participation and enhance student's learning.
\end{abstract}

Key words: classroom learning environment, instructional quality, structural equation models, student learning, student mediation.

\section{Introduction}

Research about learning environments has a long tradition of analysing psycho-social dimensions of the classroom. Psycho-social factors have proved to be significant in student learning, together with the 'quality' and 'quantity' of teaching. Further, student-related factors, such as motivation and prior learning, are also extremely important. Research about learning environments was later broadened to take account of the role of the school, home and peer group in students' achievements and attitudes (Fraser \& Kahle, 2007; Marjoribanks, 1999). The classroom environment has been shown to be the most significant factor in students' learning and attitudes (in mathematics and science) (Fraser \& Kahle, 2007). In the past, learning environment research has focused mainly on direct connections between learning outcomes and the learning environment. However, such research neglects the cognitive paradigm where teaching and its psychosocial properties are linked to student's learning via 'mediating factors,' such as studying, motivation and metacognition. These mediators can be further divided into cognitive (e.g., metacognition and prior achievement) and motivational (e.g., self-efficacy) factors. As noted by Muijis (2006), these mediating processes have also usually been overlooked in studies of teacher effectiveness. 


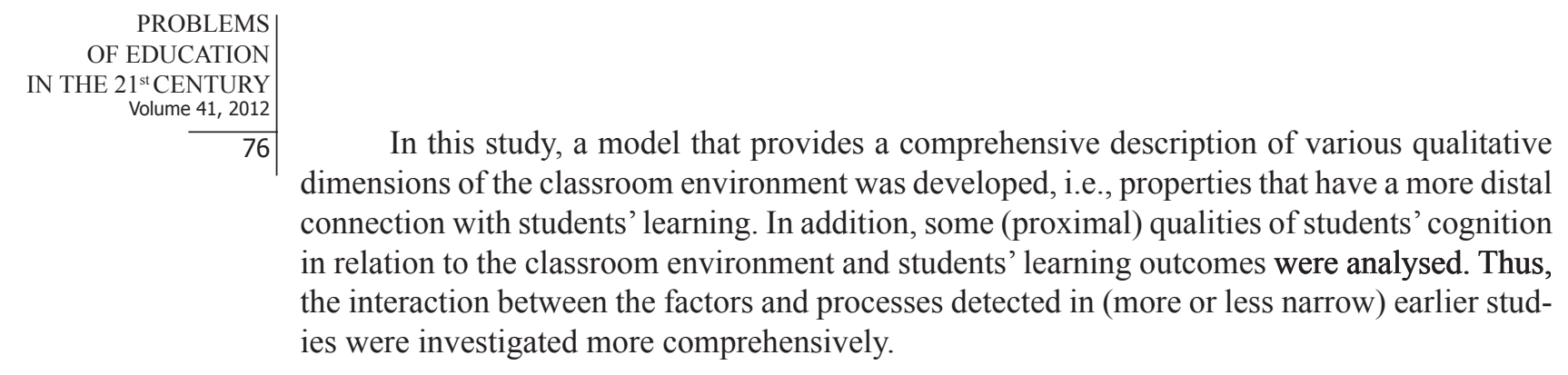

\section{Metacognitive and Constructivist Learning Environments, Students' Participation and Learning Outcomes}

The emphasis on metacognitive orientation and constructivist learning in learning environments can be viewed as a modern and student-activating approach. However, metacognitive orientation and constructivist learning can also be found in more conventional classroom environments. The application of these approaches in teaching requires active utilisation of students' cognition and motivation of the students in the use of self-direction and thinking skills. Various tools have been developed to determine the mechanisms underlying a constructivist learning environment (Aldridge, Fraser, Taylor, \& Chen, 2000; Johnson \& McClure, 2004; Nix, Fraser, \& Ledbetter, 2005) and metacognitive orientation in teaching (Thomas, 2003; Thomas \& McRobbie, 2001; Thomas \& Mee, 2005).

Thomas (2003) conceptualised, developed and validated an instrument called the metacognitive orientation learning environment scale-science (MOLE-S) to analyse the meaning of a metacognitive orientation environment in students' science learning. The study showed that metacognitive demands, student-student discourse, student-teacher discourse, student voice, shared control, teacher support and emotional support were significant variables in such an environment. However, Thomas (2003) did not consider the students' learning outcomes or their metacognition. To investigate students' metacognition in classroom teaching, Thomas and Mee (2005) manipulated the students' learning environment. Although the manipulation was not entirely successful, they noted some changes in the students' metacognitive knowledge and processes based on interviews with the students and classroom observations. Thomas (2003) also highlighted the need to develop instruments such as the MOLE-S for other subjects. Thus, the development of metacognitive skills is important in areas other than science teaching.

In an experimental study of the constructivist learning environment (personal relevance, student control), Ogbuehi and Fraser (2007) reported that involvement and task orientation in the classroom had a positive effect on developing students' attitudes in learning mathematics. In the same study, shared control, student negotiation and the orientation of the investigation had positive effects on cognitive learning outcomes. Spinner and Fraser (2005) conducted an experimental study in which they used an innovative constructivist approach to analyse dimensions of the learning environment, such as collaboration, understanding orientation, personal relevance, shared control, participation and personalisation. Their results showed that the students in the study group were more oriented to conceptual development compared with a control group.

According to the learning theory of Nuthall and Alton-Lee (1993), students learn when they encounter certain learning experiences (at least 3-4 times), making a connection with their prior cognitive structure. The main thesis of their theory is that differences in students' learning outcomes are the result of differences in their (real) participation. The variation in students' participation is viewed as the most important component, even within a class, when comparing the differences in learning outcomes (Nuthall, 1999a, 1999b). Engle (2006) also investigated the temporal nature of learning contexts and the motivation of students to participate in intellectual conversation, as well as the transfer effect in learning and how teachers can support this effect. This study validated the findings of Nuthall (1999a, 1999b), showing that the teacher is able to frame the learning context in student-applicable contexts that the student learned earlier. 
Harri PITKÄNIEMI, Petteri VANNINEN. Learning Attainments as a Result of Student Activity, Cognition and the Classroom Environment

\section{Psycho-social Dimensions of the Classroom Environment, Teaching and Students'Learning}

Outcomes

PROBLEMS

OF EDUCATION

IN THE $21^{\text {st }}$ CENTURY

Volume 41, 2012

John, Frances, and Hin-wah (2003) investigated the relationship between students' perceptions of the classroom environment and their learning outcomes and self-esteem. They analysed classroom dimensions, such as the level of collaboration, involvement, teacher involvement and teacher support. Teacher involvement had the most significant association with learning outcomes (Chinese, foreign language and mathematics). The level of collaboration also had a statistically significant effect on learning outcomes. In another study, Goh and Fraser (1998) reported that factors such as teacher leadership, helpfulness/friendliness and empathy were positively correlated with students' cognitive outcomes.

According to Meyer and Turner (2006), engaging students in learning requires consistently positive emotional experiences. Such experiences contribute to the climate in the classroom and form the foundation for teacher-student relationships and the interactions necessary for the motivation to learn. In a comprehensive study by Chionh and Fraser (2009), enhanced student cohesiveness in the classroom was associated with better examination scores in mathematics and geography. Further, in this study, students' self-esteem and attitudes were better in classrooms where there was more teacher support, task orientation and equity. Rita and Martin-Dunlop (2011) also reported that teacher support, investigation and equity were all statistically significant independent predictors of students' achievement. However, cohesiveness had a negative effect, which might be because their sample included 'gifted' students.

\section{Learning Environment, Students' Cognition, Students 'Motivation and Learning Results}

In general, metacognition has not been systemically studied (see Thomas \& Mee, 2005 ) in learning environment research, despite metacognitive skills apparently developing and contributing to learning (Thomas \& McRobbie, 2001; Veenman, Wilhelm, \& Beishuizan, 2003). From an early age, students begin to evaluate their own abilities and eventually acquire a sense of self-efficacy (Bandura, 1997; Pajares, 1997). Bandura (1997), Nichols (1996) and Pajares (1997) argued that perceptions of self-efficacy have a positive impact on students' motivation and achievement. A few studies have investigated the relationship between students' self-efficacy and psycho-social learning environments (Dorman, 2001; Dorman, Fisher, \& Waldrip, 2006; Ferguson \& Dorman, 2001). One of these studies investigated the association between students' self-efficacy and learning outcomes (Moriarty, Douglas, Punch, \& Hattie, 1995). In the study by Dorman et al. (2006), task orientation, teacher support, equity and the students' cohesiveness were related with academic efficacy and relevant evaluation, as well as with a positive attitude toward science. In an earlier study by Dorman (2001), teacher support, involvement, investigation, task orientation and equity were all positively correlated with students' academic efficacy. Students' perceptions about task orientation, involvement and investigation were also positively correlated with academic efficacy in a study by Ferguson and Dorman (2001). Moriarty et al. (1995) reported a certain 'mediative variable', i.e., academic efficacy, between teaching and students' learning. Thus, collaborative teaching is better than competition or working alone in terms of students' academic efficacy and learning outcomes (social studies). In relation to mathematics, Opolot-Okurut (2010) reported that teacher support, as well as involvement, task orientation and equity, was associated with learning motivation.

The climate in a classroom does not have a direct effect on academic achievements, but motivates the students, thereby catalysing the learning process. For example, Brok, Brekelmans, and Wubbels (2004) reported that students' perceptions of the level of collaboration by the teacher are very meaningful in terms of their own motivation. In the research context of teaching mathematics, Schweinle et al. (2006) concluded that students' motivation is related 
PROBLEMS

OF EDUCATION

IN THE $21^{\text {st }}$ CENTURY

Volume 41, 2012

78

to properties of teaching discourse, such as substantive feedback, social relatedness and an emphasis on learning for its own sake. Self-efficacy can also be assumed to be a motivating factor; Anderson, Hamilton, and Hattie (2004) stated that this is correlated with characteristics of the learning environment, such as high cohesion, satisfaction, goal orientation and a low level of disorder and conflict.

It is well known that prior learning or prior achievements are one of the strongest predictors of new learning (Alexander, 1996; Araz \& Sungur, 2007; Cook, Wiebe, \& Carter, 2008; Rivet and Krajcik, 2008; Dochy, 1995; Dochy, Segers, \& Buehl, 1999). For example, Jones and Byrnes (2006) concluded that self-regulated students having strong prior achievements and a low level of frustration with mathematics benefit substantially from high-quality teaching. Similarly, Corno, Cronbach, and Kupermintz (2002) noted that the best predictor of achievement in later grades is often achievement in earlier grades.

\section{Study Goal, a Summary of Earlier Research and a Constructional Model}

The aims of the study were to:

(1) construct and test a dynamic semi-empirical model of the learning environment, outlining in detail the interactions between the learning environment, students' cognition (i.e., mediating factors) and learning, and

(2) outline the direct and indirect effects in the present model and the underlying processes determining the learning environment in the classroom.

Students' self-efficacy has been shown to have a strong association with student involvement and learning outcomes. Hence, self-efficacy was selected as a motivation factor in the present model; moreover, self-efficacy has been mainly employed in earlier learning environment studies. Students' personal relevance is also linked to motivation. The studies by Moriarty et al. (1995) and Opolot-Okurut (2010) provided support for the role of the learning environment in self-efficacy or student motivation. Further, the student-teacher relationship has been reported to be a significant factor in emotional motivation and commitment (Mayer \& Turner, 2006). In addition, in terms of metacognition and self-efficacy, emotional (relationship with the teacher, classroom climate) and management factors play important roles in the learning environment. Thomas and Mee (2005) reported that metacognitive clues in teaching have a positive effect on students' metacognition. Moreover, John, Frances, and Hin-wah (2003) reported that the level of collaboration in teaching supports students' motivation to learn. As a result, it is assumed these positive dimensions of the learning environment (conditions for studying, management and atmosphere) are essential for promoting students' learning skills and metacognition.

According to the studies above, the mediating factors at the student level are the students' self-efficacy (representing motivation) and the students' metacognition (representing the students' learning skills). It was further assumed that the classroom environment (including cognitive, constructivist and metacognitive orientation) and other factors of the learning environment (conditions for studying, e.g., management and the emotional relationship between students and the teacher) promote students' self-efficacy and metacognition, rather than having a direct effect on students' learning outcomes. It was further assumed there is a positive relationship between students' self-efficacy and students' metacognition. In other words, it is assumed that cognition (e.g., learning as a self-regulation skill) and motivation are linked. Two other factors - prior achievement (e.g., Corno et al., 2002) and student participation (Nuthall \& Alton-Lee, 1993; Engle, 2006) - were included in the model. The study by Jones and Byrnes (2006) supports the idea that metacognition (self-regulation) and students' participation in teaching are positively correlated. In common with their study, the aim here is to determine whether prior achievement promotes students' success in actual teaching situations and whether 
prior achievement is predictive of additional achievements. It was assumed that a high level of self-efficacy encourages students to participate in teaching and that utilising the learning environment increases as a result. The details of the conceptual model are presented in Figure 1.

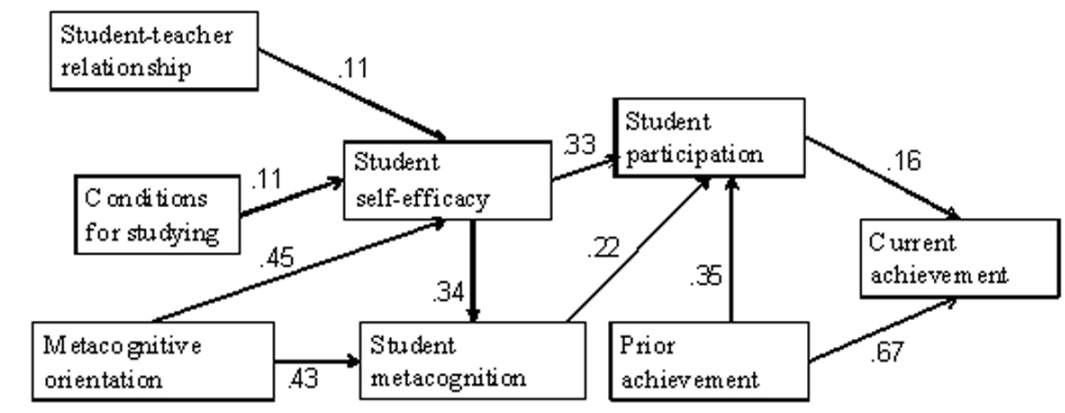

Figure 1: Conceptual model (the effects of the model are produced by the AMOS program; see data analysis in Methodology or Research).

\section{Methodology of Research}

A correlative research design was adopted in order to carry out the research task of the study. The basic essence of the study was to test the constructed model and develop it further on the basis of empirical data and theory knowledge in the framework of structural equation modelling (SEM).

\section{Sample}

The study group consisted of 218 fifth- and sixth-grade primary school students (girls, $N=116$; boys, $N=102$ ). The classrooms were randomly sampled. The data were collected from nine schools and 11 classrooms (two classrooms from the two biggest schools were sampled). Supplementation was used to maximise the utilisation of information in data. Missing data in the questionnaires were supplemented by variable means.

\section{Instruments}

A questionnaire was constructed (in Finnish), based on the conceptual model presented in Figure 1. However, in determining 'the metacognitive orientation in teaching' scale, the original items of the MOLES-S instrument (see Thomas, 2003) were used, but were translated into Finnish. The instrument was initially tested to tailor it for final use in this study. General information, such as the name of the school, the code number of the classroom and the gender of the participants, was also collected. The questionnaire used a five-point Likert scale (Almost always-Almost never) derived from six theoretical concepts. The scale and the questionnaire items are presented in Table 1.

In addition, the students were asked about their examination grades in mathematics, history and native language for the previous year (i.e., one year ago) (three summative evaluations were constructed for each subject according to information provided by the students' teacher). The sum variable 'Prior achievement' was constructed from earlier grades; hence, it describes the average achievement in these three subjects one year ago. Correspondingly, the sum variable 'Current achievement' was constructed based on recent grades in these subjects. The descriptive statistics from the variables are presented in Table 2. 
Table 1. Scale, number of items and the instrument's reliability.

\begin{tabular}{|l|c|c|}
\hline \multicolumn{1}{|c|}{ Scale } & $\begin{array}{c}\text { Number of } \\
\text { items }\end{array}$ & $\begin{array}{c}\text { Consistent reliability, } \\
\text { Cronbach alpha, a }\end{array}$ \\
\hline $\begin{array}{l}\text { Student participation } \\
\text { "My participation in lessons is good." }\end{array}$ & 7 & 0.87 \\
\hline $\begin{array}{l}\text { Student metacognition } \\
\text { "I monitor that I have understand, for example, study book." }\end{array}$ & 4 & 0.75 \\
\hline $\begin{array}{l}\text { Student self-efficacy } \\
\text { "I think I am good at doing things." }\end{array}$ & 4 & 0.78 \\
\hline Metacognitive orientation in teaching & & 0.84 \\
\hline $\begin{array}{l}\text { Metacognitive demands } \\
\text { "The teacher asks me or the other students to think about } \\
\text { how to learn best." }\end{array}$ & & \\
$\begin{array}{l}\text { Student-student discourse } \\
\text { Student-teacher discourse } \\
\text { Student voice } \\
\text { "I can tell my teacher if I do not understand something." } \\
\text { Shared control } \\
\text { "I feel I can contribute to understanding the topic we are sup- } \\
\text { posed to learn about in the lesson." }\end{array}$ & & \\
\hline $\begin{array}{l}\text { Conditions for studying } \\
\text { "Our classroom is a peaceful place to work." }\end{array}$ & & \\
\hline $\begin{array}{l}\text { Student-teacher relationship } \\
\text { "The teacher views the students as equals." }\end{array}$ & 4 & \\
\hline
\end{tabular}

\section{Data Analysis}

The Statistical Package for Social Sciences (SPSS, version 17.0) was used to analyse the descriptive statistics of variables. The mean, standard deviation, skewness and kurtosis of each variable in the model are displayed in Table 2. Structural Equation Modelling (SEM) was used to analyse the data of the proposed conceptual model and the re-specified model. SEM analysis allows a researcher to specify the relationships among variables included in a model. In this research context, the proposed theoretical model of current achievement was specified and then tested. Another intent is that a researcher use SEM modelling to establish the direct and indirect effects of each variable included in a model construction. Further, a comparison of the relative effects of specific variables in the model can also be analysed. A path analysis of the conceptual model was conducted using the AMOS program, version 18.0.0.

Table 2. Descriptive statistics with respect to the classroom learning environment, motivational, cognitive and achievement variables.

\begin{tabular}{|l|c|c|c|c|}
\hline \multicolumn{1}{|c|}{ Variables } & M & SD & Skewness & Kurtosis \\
\hline Student participation & 3.86 & 0.62 & -0.25 & -0.01 \\
\hline Student self-efficacy & 3.11 & 0.55 & -0.43 & -0.08 \\
\hline Student metacognition & 2.81 & 0.61 & -0.18 & -0.17 \\
\hline Metacognitive orientation & 3.28 & 0.53 & -0.00 & -0.37 \\
\hline Study conditions & 2.71 & 0.65 & -0.43 & 0.11 \\
\hline Student-teacher relationship & 3.10 & 0.83 & -0.61 & -0.58 \\
\hline Prior achievement & 8.05 & 0.78 & -0.12 & 0.02 \\
\hline Current achievement & 8.24 & 0.87 & -0.22 & -0.74 \\
\hline
\end{tabular}




\section{Results of the Research}

The goodness of fit measures presented in Table 3 indicate the initial conceptual model, which was based on previous research from a variety of research traditions, did not fit the data very well. However, even this tentative model included mostly statistically significant effects (Figure 1). Based on these tentative results, the model was modified (Figure 2) to eliminate all non-significant paths, and a few additional pathways were hypothesised. As shown in Table 3, the revised model showed an acceptable fit.

Table 3. Measures of the model's fit.

\begin{tabular}{|l|c|c|c|c|c|c|}
\hline Model & $\chi^{2}$ & df & $\mathbf{p}$ & CMIN/DF & NFI & RMSEA \\
\hline Conceptual model & 143.66 & 18 & 0.00 & 7.98 & 0.77 & 0.18 \\
\hline Revised model & 25.67 & 14 & 0.03 & 1.83 & 0.96 & 0.06 \\
\hline
\end{tabular}

As the goodness of fit indices for the revised model provided evidence that this model is an adequate fit to the data, standardised path coefficients for the direct, indirect and total effects of each factor were calculated. The results of the analysis are displayed in Table 4, and the standardised path coefficients for the direct effects are graphically presented in Figure 2.

Next, the modified model was considered based on assumptions and earlier findings presented in the theoretical part of the present study. The revised model (Figure 2) and the conceptual model (Figure 1) were not contradictory in any way, but the revised model utilised the modification indices according to empirical data whenever theoretical knowledge existed for these modifications. It is possible some suggested modifications by AMOS program may have been overlooked, the theory basis of which might not have been realised. In any case, the data in the revised model unequivocally supported certain powerful concepts in educational psychology and the relationships between those concepts, which were identified in earlier studies. The relationship between prior achievement and current learning outcomes was the strongest ( $\beta=$ 0.67). Prior learning improves students' participation in teaching $(\beta=0.36)$ and this further enhances new learning $(\beta=0.17)$. It seems that students' participation as a variable does not reflect all the activities and cognition (i.e., studying) necessary for students to learn. Self-efficacy and metacognition scored high in terms of goal-oriented thinking and action. A student's selfefficacy describes the motivational strength and his/her intention to manage studying. Metacognitive thinking supports the students' participation in classroom teaching and active orientation. In fact, students' participation can augment metacognition. However, metacognition in students may also be 'invisible.' As a student's self-efficacy grows, so too does his/her intention to monitor and develop his/her studies. Thus, metacognitive thinking also increases. As a result, motivational and cognitive factors are essential in studying and in classroom activities.

In addition to emphasising some well-known factors in educational psychology (i.e., proximal factors) associated with student learning, it is also important to comprehensively outline the relationships between those factors in the learning environment (i.e., distal factors). The present conceptual model contains relationships, in common with earlier studies, where certain variables in the classroom learning environment are linked to mediative factors in students' cognition, i.e. in developing students' self-efficacy and metacognition. The present model and data support these conclusions. They showed that having a good relationship with the teacher motivates students and makes it easier for them to reflect on self-efficacy in relation to their learning skills $(\beta=0.11)$. Further, conditions for studying, i.e., an environment that allows students to concentrate, study and work in peace, promoted students' self-efficacy ( $\beta=$ 0.13). In general, the aforementioned factors (student-teacher relationship, study conditions) form the framework to facilitate high-quality instruction. In this study, the quality of teaching 
was operationalised through the concept of 'metacognitive orientation in teaching.' This approach consists of features other than conventional teaching activities to encourage students' thinking skills and to promote students' own interest in metacognitive study. If the students perceived metacognitive orientation in their classroom environment, they also exhibited metacognitive thinking ( $\beta=0.42$ ). In addition, by activating the students' thinking skills, the factor 'metacognitive orientation in teaching' also seemed to promote the students' feelings of self-efficacy $(\beta=0.47)$.

There was no remarkable difference between the revised model and the conceptual model in terms of the findings noted above. In utilising the modification indices of the AMOS program, it is challenging for the researcher, in order to be critical, to remain logical and to ensure the changes input in the model are theory-based. As a result of deduction, the following changes were made to the conceptual model: a) some relationships between variables of classroom learning environment were added, and b) two variables that affect students' participation were added.

Table 4. Direct, indirect and total effects of variables included in the best-fitting model of current achievement.

\begin{tabular}{|l|c|c|c|}
\hline Variable & Direct & Indirect & Total \\
\hline Prior achievement & 0.67 & 0.06 & 0.73 \\
\hline Student participation & 0.36 & & 0.36 \\
\hline Student self-efficacy & & 0.04 & 0.04 \\
\hline Student metacognition & & 0.02 & 0.02 \\
\hline Student-teacher relationship & & 0.03 & 0.03 \\
\hline Study conditions & & 0.01 & 0.01 \\
\hline Metacognitive orientation & & 0.08 & 0.08 \\
\hline
\end{tabular}

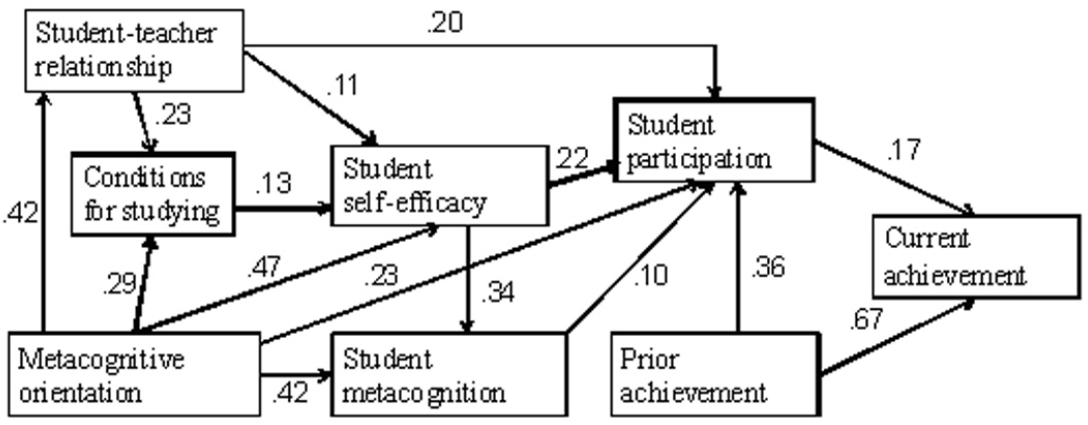

Figure 2: Re-specified model.

It is clear that, in addition to students' own decision making and motivation to participate in teaching, a teacher can emotionally and cognitively - even spontaneously - promote students' engagement in classroom situations. In terms of this type of classroom environment in the current study, the findings revealed evidence of metacognitive orientation in teaching $(\beta=0.23)$ and a student-teacher relationship $(\beta=0.20)$. If metacognitive orientation in teaching encouraged the students to study $(\beta=0.29)$, and if the student-teacher relationship was considered supportive and warm $(\beta=0.23)$, then both were associated with the ability to work and to concentrate on the topic at hand. It is probable that metacognitive orientation in teaching also promotes the meaningfulness of study and activates students' thinking skills. This positive experience further enhances students' relationships with the teacher $(\beta=0.42)$. 


\section{Discussion}

A model that comprehensively describes the relationship between the classroom learning environment, student's cognition and learning outcomes was constructed in this study. The model was developed to include the student factors involved in the mediation processes. The findings will aid understanding of the underlying mechanisms that affect students' learning in the classroom. Students' cognitive-motivational mediation must be emphasised because, in its absence, the effects of teaching seem to ostensibly have quite a minor role. However, teaching cannot affect students' learning without their active cognition, participation, etc. The inclusion of mediation mechanisms, i.e., the cognitive and motivational variables, in studies will make the teaching-learning relationship more explicit than in studies where they are not included. For example, the data here showed that the properties of the learning environment - the studentteacher relationship, study conditions and meta-cognitive orientation towards teaching - correlate statistically quite weakly with the students' learning achievements. However, all the student mediation factors, i.e., metacognition and self-efficacy, showed a significant statistical correlation with the variable of student learning.

The presented conceptual model is based on prior research, which mainly focused on the relationship between the features of the learning environment and students' self-efficacy (e.g., Moriarty et al., 1995; Dorman, 2001; Dorman, et al. 2006). Many educational psychology studies have reported variables - prior learning, self-efficacy and metacognition - that are able to relatively strongly predict students' learning. Thus, several factors could be used to build the conceptual (theoretical) model to ensure the relationships present in the model will appear. As noted, the revised model does not conflict with the so-called theoretical model, i.e., the new model mainly elaborates on the broad category of the effects of the learning environment. These effects relate to the three factors in Figure 2 (note the connections represented in the model in the crosswise direction). According to the present model, a metacognitive orientation in teaching and teacher-student-relationships will encourage students to concentrate on the teaching; in other words, the conditions for students to study are good. It is interesting and important to note that certain features of the learning environment (metacognitive orientation in teaching and the student-teacher relationship) can affect students' participation.

However, a number of methodological limitations, which can be addressed in future studies, need to be considered. First, all data for this study was collected at one time. Thus, the relationships between the elements in the model were estimated based on a correlative research design, i.e. the effects of 'one direction' may not be valid or even necessarily realistic in many parts of the model. However, the conceptual model in the study focused on the effects of teaching, student mediation, and on a broad range of empirical research. Second, the learning environment was studied in relation to a few subjects (a sum variable derived from a few school subjects), whereas earlier studies often focused on specific subjects, such as mathematics or science. Therefore, the findings of the revised model may not be comparable with those of models incorporating specific subject matter. Third, the learning achievements of the students were based on scores and school grades given by their class teachers. These can be considered quite a 'coarse' indicator of learning in the scientific sense. Fourth, the research instrument, although based on careful planning and on preliminary testing with students of the same age, was dissimilar to the measuring instruments used in earlier studies, and it was not based on the items contained in those studies. Only the measurement of metacognitive orientation in teaching included a few items used in the measurement instrument used by Thomas (2003). Despite this, the estimated reliability of the coefficients in the variables was sufficient (min. $\alpha, .75$; $\max . \alpha, .87)$.

To further develop the research framework and increase understanding of factors important in the learning environment, it would be rewarding to study the relationships detected in 
PROBLEMS

OF EDUCATION

IN THE $21^{\text {st }}$ CENTURY

Volume 41, 2012

84

this correlative design in manipulative research frames, i.e. an experimental design or a longitudinal design, and, for example, in case studies or activity research. In addition, studies of a variety of subjects (e.g., languages, mathematics, science and social studies) would aid comparative research designs. For example, the objectives of social studies learning are somewhat different to those of mathematics in terms of the essence of learning. Such differences influence what constitutes an ideal learning environment.

\section{Conclusions}

The building and testing of the relatively comprehensive conceptual model described in this paper is an example of a systemic approach to educational research. The systemic approach means that not only part of the phenomenon, but the wholeness is studied (Salomon, 2006). Therefore, it is necessary to study the network of relationships rather than e.g., the relationship between two individual variables. In other words, for example, a certain individual student's overall situation can be described with the help of good "network" where many factors help the student study interactively in the classroom context. Strictly speaking, and orienting more towards generalisations, it is possible to imagine that there are usually several "students with networks of good development" and unfortunately also "students with networks of bad development" in one school. In this regard, this study tries to help researchers and practitioners understand a complex, interactive and comprehensive phenomenon in classroom learning environments.

It is challenging to build a structural equation model that represents the relationships between learning environment, student mediation and learning outcomes, as such a broad model requires assumptions about and measurements of many variables. When constructing a model, combining separate studies and their findings from diverse research traditions is not a simple task. Even If the comprehensive model is built using meta-analytic studies, it does not guarantee that the model will be compatible with the empiric data. Nonetheless, previous high-quality investigations of separate relationships well supports the possibility that the systemic model will work. It is important to realise the systemic nature of the phenomenon at a conceptual level. On the other hand, it is also essential to try to verify dynamic relationships between many factors. This conclusion is supported by the research validity (i.e., coverage of the phenomenon and interactive relationships between the factors) and also from a practical point of view (mostly teachers). In practice, a skilful teacher will operate and think based on a systemic point of view rather than based on only the control of one factor or a narrow research area.

\section{References}

Aldridge, J., Fraser, B., Taylor, P., \& Chen, C.-C. (2000). Constructivist learning environments in a crossnational Study in Taiwan and Australia. International Journal of Science Education, 22, 37-55.

Alexander, P.A. (1996). The past, present, and future of knowledge research: a re-examination of the role of knowledge in learning and instruction. Educational Psychologist, 31, 89-92.

Anderson, A., Hamilton, R. J., \& Hattie, J. (2004). Classroom climate and motivated behaviour in secondary schools. Learning Environments Research, 7, 211-225.

Araz, G., \& Sungur, S. (2007). The interplay between cognitive and motivational variables in a problembased learning environment. Learning and Individual Differences, 17, 291-297.

Bandura, A. (1997). Self-efficacy: The exercise of control. New York: WH Freeman.

Brok, P., Brekelmans, M., \& Wubbels, T. (2004). Interpersonal teacher behaviour and student outcomes. School Effectiveness and School Improvement, 15, 407-442. 
Chionh, Y., Fraser, B. (2009). Classroom environment, achievement, attitudes and self-esteem in geography and mathematics in Singapore. International Research in Geographical and Environmental Education, 18, 29-44.

Cook, M., Wiebe, E. N., \& Carter, G. (2008). The influence of prior knowledge on viewing and interpreting graphics with macroscopic and molecular representations. Science Education, 92, 848-867.

Corno, L., Cronbach, L. J., \& Kupermintz, H. (2002). Remaking the concept of aptitude: Extending the legacy of Richard E. Snow. Mahwah, NJ: Lawrence Erlbaum.

Dochy, F. (1995). Prior knowledge and learning. In L.W. Anderson (Ed), International encyclopaedia of teaching and teacher education (pp. 382-386). Cambridge: Pergamon.

Dochy, F., Segers, M., \& Buehl, M. M. (1999). The relation between assessment practices and the outcomes of studies: The case of research on prior knowledge. Review of Educational Research, $69,145-186$.

Dorman, J. (2001). Associations between classroom environment and academic efficacy. Learning Environments Research, 4, 243-257.

Dorman, J. P., Fisher, D. L., \& Waldrip, B. G. (2006). Classroom environment, students' perceptions of assessment, academic efficacy and attitude to science: a LISREL analysis. In D. Fisher \& M.S. Khine (Eds.), Contemporary approaches to research on learning environments (pp. 1-28). Singapore: World Scientific.

Engle, R.A. (2006). Framing interactions to foster generative learning: A situative explanation of transfer in a community of learners classroom. Journal of the Learning Sciences, 15, 451-498.

Ferguson, J.M., \& Dorman, J.P. (2001). Psychosocial classroom environment and academic efficacy in Canadian high school mathematics classes. Alberta Journal of Educational Research, 47, 276279.

Fraser, B.J., \& Kahle, J.B. (2007). Classroom, home and peer environment influences on student outcomes in science and mathematics: An analysis of systemic reform data. International Journal of Science Education, 29, 1-19.

Goh, S., \& Fraser, B. (1998). Teacher interpersonal behavior: Classroom environment and student outcomes in primary mathematics in Singapore. Learning Environments Research, 1, 199-229.

John, L., Frances, L., \& Hin-wah, W. (2003). Development of a classroom environment scale in Hong Kong. Educational Research and Evaluation, 9, 317-344.

Johnson, B., \& McClure, R. (2004). Validity and reliability of a shortened, revised version of the constructivist learning environment survey (CLES). Learning Environment Research, 7, 65-80.

Jones, K.K., \& Byrnes, J.P. (2006). Characteristics of students who benefit from high-quality mathematics instruction. Contemporary Educational Psychology, 31, 328-343.

Marjoribanks, K. (1999). Environmental and individual influences on adolescents' aspirations: A moderation-mediation model. Learning Environments Research, 2, 43-64.

Meyer, D.K., \& Turner, J.C. (2006). Re-conceptualizing emotion and motivation to learn in classroom contexts. Educational Psychology Review, 18, 377-390.

Moriarty, B., Douglas, G., Punch, K., \& Hattie, J. (1995). The importance of self-efficacy as a mediating variable between learning environments and achievement. British Journal of Educational Psychology, 65, 73-84.

Muijs, D. (2006). Measuring teacher effectiveness: Some methodological reflections. Educational Research and Evaluation, 12, 53-74.

Nichols, J.D. (1996). The effects of cooperative learning on student achievement and motivation in a high school geometry class. Contemporary Educational Psychology, 21, 467-476.

Nix, R., Fraser, B., \& Ledbetter, C. (2005). Evaluating an integrated science learning environment using the constructivist learning environment survey. Learning Environments Research, 8, 109-133.

Nuthall, G., \& Alton-Lee, A. (1993). Predicting learning from student experience of teaching: A theory of student knowledge construction in classrooms. American Educational Research Journal, 30, 799-840. 
PROBLEMS

OF EDUCATION

IN THE $21^{\text {st }}$ CENTURY

Volume 41,2012

Nuthall, G. (1999a). Learning how to learn: the evolution of students' minds through the social processes and culture of the classroom. International Journal of Educational Research, 31, 141-256.

Nuthall, G. (1999b). The way students learn: Acquiring knowledge from an integrated science and social studies unit. Elementary School Journal, 99, 303-341.

Ogbuehi, P. I., \& Fraser, B. (2007). Learning environment, attitudes and conceptual development associated with innovative strategies in middle-school mathematics. Learning Environment Research, 10, 101-114.

Opolot-Okurut, C. (2010). Classroom learning environment and motivation towards mathematics among secondary school students in Uganda. Learning Environments Research, 13, 267-277.

Pajares, F. (1997). Current directions in self-efficacy research. In M. Maehr \& P. R. Pintrich (Eds.), Advances in motivation and achievement (pp. 1-49). Greenwich, CT: JAI Press.

Rita, R., \& Martin-Dunlop, C. (2011). Perceptions of the learning environment and associations with cognitive achievement among gifted biology students. Learning Environments Research, 14, $25-$ 38 .

Rivet, A.E., \& Krajcik, J.S. (2008). Contextualising instruction: Leveraging students' prior knowledge and experiences to foster their understanding of middle school science. Journal of Research in Science Teaching, 45, 79-100.

Salomon, H. (2006). The systemic vs. analytic study of complex learning environments. In J. Elen \& R.E. Clark (Eds.), Handling complexity in learning environment: Theory and research. Advances in learning and instruction (pp. 255-264). Oxford: Elsevier.

Schweinle, A., Meyer, D. K., \& Turner, J. C. (2006). Striking the right balance: Students' motivation and affect in elementary mathematics. Journal of Educational Research, 99, 271-293.

Spinner, H., \& Fraser, B. (2005). Evaluation of an innovative mathematics program in terms of classroom environment, student attitudes, and conceptual development. International Journal of Science and Mathematics Education, 3, 267-293.

Thomas, G. P. (2003). Conceptualisation, development and validation of an instrument for investigating the metacognitive orientation of science classroom learning environments: the metacognitive orientation learning environment scale - science (MOLES-S). Learning Environments Research, 6, 175-197.

Thomas, G. P., \& McRobbie, C. J. (2001). Using a metaphor for learning to improve students' metacognition in the chemistry classroom. Journal of Research in Science Teaching, 38, 222-259.

Thomas, G. P., \& Mee, D. A. (2005). Changing the learning environment to enhance students' metacognition in Hong Kong primary school classrooms. Learning Environments Research, 8, 221-243.

Veenman, M., Wilhelm, P., \& Beishuizan, J. (2003). The relation between intellectual and metacognitive skills from a developmental perspective. Learning and Instruction, 13, 89-109.

Advised by Vincentas Lamanauskas, University of Siauliai, Lithuania
Accepted: March 13, 2012

Harri Pitkäniemi

PhD, Professor, University of Eastern Finland, Kuninkaankartonkatu 7, Box 86, 57101 Savonlinna, Finland.

E-mail: harri.pitkaniemi@uef.fi

Petteri Vanninen

E-mail: petteri.vanninen@uef.fi 